\title{
The Incentive Problems Study of the Employees of the New Generation under the Structure of Grade in China
}

\author{
Qing Xia, Hongyan Li \\ College of Management, Shanghai University of Engineering Science, Shanghai, China. \\ Email: xiaqingok@163.com, lihongyan580@sohu.com
}

Received October $25^{\text {th }}, 2013$; revised November $24^{\text {th }}, 2013$; accepted November $30^{\text {th }}, 2013$

Copyright (C) 2013 Qing Xia, Hongyan Li. This is an open access article distributed under the Creative Commons Attribution License, which permits unrestricted use, distribution, and reproduction in any medium, provided the original work is properly cited. In accordance of the Creative Commons Attribution License all Copyrights (C) 2013 are reserved for SCIRP and the owner of the intellectual property Qing Xia, Hongyan Li. All Copyright (C) 2013 are guarded by law and by SCIRP as a guardian.

\begin{abstract}
The incentive problems of the employees of the new generation are increasingly becoming the focus of managers, because they go to work and gradually become the main force in the labor market. However, special social-economic background has given the crowd a few generational features, which require us to explore the incentive work of the new generation with a whole new perspective. In addition, our country is a country which attaches great importance to the cultural inheritance and the traditional national culture deeply affects every generation in different degree. The social structure of the structure of grade as an important part of traditional Chinese culture is bound to be a unique impact on the employees of the new generation. So, this paper will elaborate the incentive problems of the new generation mainly from the perspective of the China's social structure (the structure of grade) and theory of cognitive dissonance.
\end{abstract}

Keywords: The Structure of Grade; The Employees of the New Generation; Theory of Cognitive Dissonance

\section{Introduction}

The incentive problem of the employees is a well-lasting hot topics and it is an important part of human resource management. Through literature review, we find that motivation theory research content is being used by one-sided shift multi-disciplinary: from a more one-sided "Contenttype incentive theory" and "process driving theory" to "comprehensive incentive model" [1]. On the incentive model, Chinese scholar Xu Jiliang proposed the interactive "I-A-R" incentive model [2]. In the "I-A-R" ("interests-Request-reward") incentive model, leaders use the appropriate incentives, to strengthen employees' behavior, and guide employees' psychological awareness, so as to achieve an effective incentive [3]. For the employee incentive, Gary P. Latham also proposed to consider the employee's personal cognitive and emotional, and many other factors. If we ignore the knowledge of individual employees, motivating employees is unable to meet the demand [1]. In addition, employee motivation is happening in certain social and cultural environment, if it is detached from the social and cultural environment factors, incentive effect will be significantly weakened. So, this paper will elaborate the incentive problems of the new generation mainly from the perspective of the China's social structure (the structure of grade) and theory of cognitive dissonance.

\section{Interaction of the Structure of Grade and the Employees of the New Generation}

\subsection{The Structure of Grade}

Fei Xiaotong put forward our traditional society is the structure of grade and it is a country with horizontal and vertical structure [4]. Horizontal "layer" refers to the relationship, and vertical "sequence" refers to a power distance. Horizontal "layer" is measured by the relationship of power centers; vertical "sequence" is measured by the power center distance. The intimate relationship between employees and the power centers showed superior intimate confidant. The distance between employees and the centers of power nearly showed a skeleton staff for the leader [5].

In our traditional society, the relationship is built on blood, geographical above. In modern society, the relationship's origins are diverse: "blood", "marriage", "karmic", "interest", etc. are playing a core role. Group 
structure is rigidly stratified. This is not going to change. So, people want to get the relationships and power. In a word, people pay attention to relations and power for such a structure.

\subsection{The Employees of the New Generation}

There is a considerable controversy for definition of the employees of the new generation. However, according to the historical background and major events to divide the new generation of people in the academic community is unanimously approved [6]. Based on these, the new generations of employees are people born after the reform and opening in this article [7]. Under the influence of special general environmental factors (social, political, cultural, economic, technological and other factors) (see Figure 1), the employees of the new generation do not have a fixed pattern of behavior, called the younger generation [8]. They do not have preconceived notions, broad interests, thoughts and actions change quickly. In addition, they have a number of important features.

\section{Generation Characteristics of the Group}

1) High need for achievement

They grow in a particular environment, so that they have a high need for achievement. Desire for achievement, for the successful pursuit is much higher than their parents, grandparents. In such a high need for achievement motivation of domination, the structure of grade has a certain influence for them. For their own success, they establish their own social network. This social network contains a horizontal "layer" and vertical "sequence" [9]. On the one hand, they have a yearning for power needs. We can give them the power to be able to motivate them.

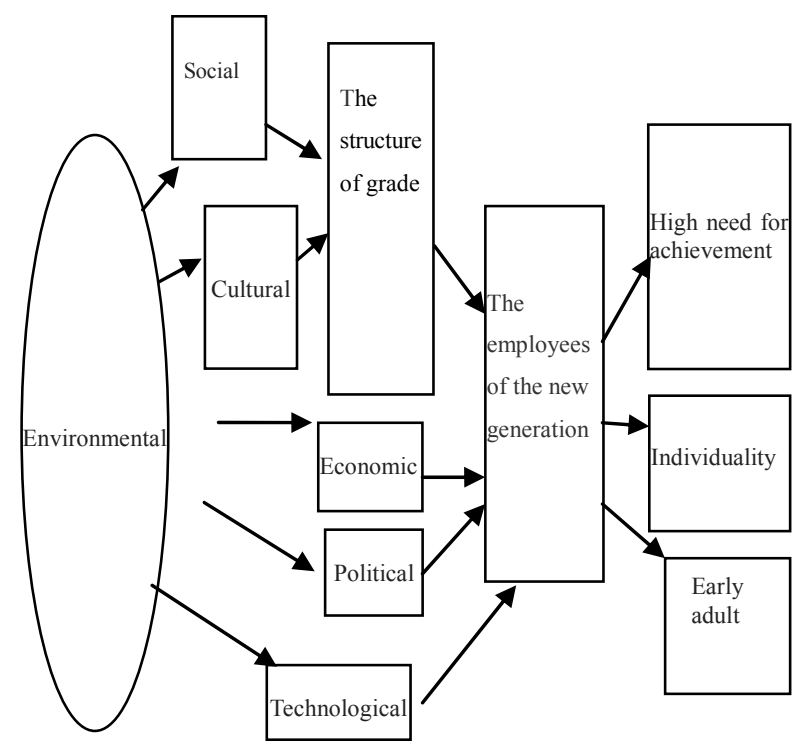

Figure 1. Characteristics of the new generation.
On the other hand, the majority of this population is the professional talent. Apart from powers, they have a loyalty to their profession.

However, the need for achievement of the employees of new generation mainly refers to the chase of power and the interests in this article.

2) Individuality

The employees of new generation have a strong idea of individuality. They are concerned about personal development. At the same time, they also have the spirit of collectivism. They want the individual and the collective is a win-win relationship [10]. They are concerned about their career development and dare to fight for their legitimate interests. They do not like to work overtime and do not want their private time is occupied by work. At the same time, they also know how to collaborate with team members to complete tasks [11].

3) Early adult

With development of information technology and changes in educational philosophy make them prematurely exposed to the adult world. Adult survival and development "game rules" had a major impact on them [12]. They are concerned about relationships and power. Because they emphasize the value of the actual needs [13].

In short, they have a high need for achievement, they emphasize individuality. At the same time, they want to be respected and premature deeply affected by the adult world.

\subsection{Interaction of the Structure of Grade and the Employees of the New Generation}

China is a country attaches great importance to cultural heritage. Therefore, they must be still deeply affected by the structure of grade (See Figure 2).

Figure 2 is constituted by the three dimensions: Distance from the center of power (D), Relations with the

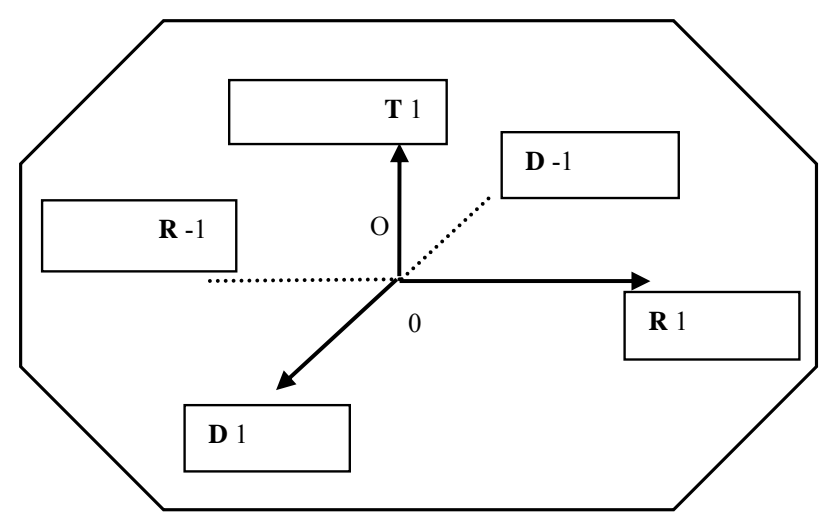

Figure 2. Interaction of the structure of grade and the employees of the new generation. 
centers of power(R), the employees of the new generation (T).

In the figure, $-1,0,1$ to explain $\mathrm{D}, \mathrm{R} . \mathrm{T}=1$ means that employees of the new generation. $\mathrm{O}$ represents a $(\mathrm{R}$ $=0, \mathrm{D}=0, \mathrm{~T}=1)$. For example $(\mathrm{R}=1, \mathrm{D}=0, \mathrm{~T}=1)$, said: a close relationship with the leadership, moderate power distance, employees of the new generation.

In the structure of grade, according to rely on their own subordinates and the ability of subordinates, managers allocate resources [14]. Therefore the structure of grade had an impact on the employees of the new generation directly. In order to achieve their goals, they are concerned about relationships and power. Create effects model function: $\mathrm{M}=\mathrm{F}(\mathrm{R}, \mathrm{D}, \mathrm{T})$, to explore interaction of the structure of grade and the employees of the new generation. $\mathrm{M}>0$ indicates a positive impact force; $\mathrm{M}=0$ means no influence; $\mathrm{M}<0$ represents produce negative influence.

1) When $R=1, D=1, M=F(R=1, D=1, T)$ values

At this time, the staff is both confidant and go-getters of superiors [5], M>0. In order to maintain vested interests, employees tend to work hard.

2) When $R=-1, D=1, M=F(R=-1, D=1, T)$ values

At this point, the staff is superior skeleton staff rather than cronies. $\mathrm{T}=1, \mathrm{M}$ may have both positive and negative. First, the staff put focus on relationships, $0<\mathrm{M}$ $<\mathrm{M}_{\max }$. Second, the employee does not pay attention to the relationship, $\mathrm{M}<0$.

3) When $R=1, D=-1, M=F(R=1, D=-1, T)$ values

This case, the staff is superior cronies. The value of $\mathrm{M}$ first increased and then decreased (See Figure 3). Figure 3 , $\mathrm{P}$ represents the time dimension. $\mathrm{M}$ is a lower and upper bound.

4) When $R=-1, D=-1, M=F(R=-1, D=-1, T)$ values

Employees are neither cronies nor skeleton staff. At this time, the stability of employees is the worst, $\mathrm{M}<0$

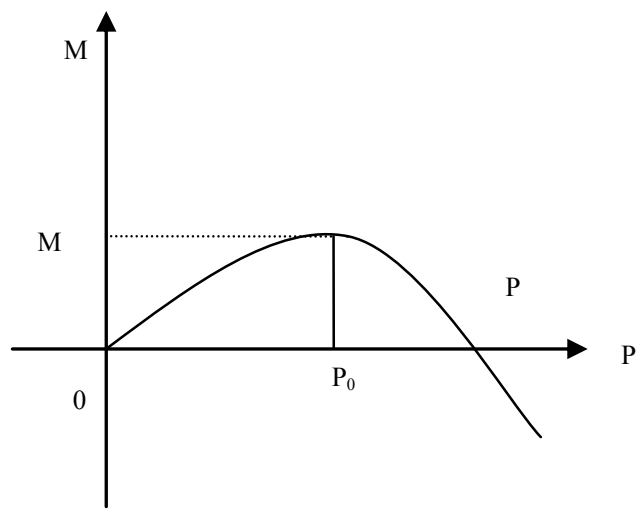

Figure 3. Under the influence of emotional images of $M$. or $\mathrm{M}=0$, employees were marginalized, and employees have no advantage in the allocation of resources.

\section{The Incentive of the New Generation under the Structure of Grade and Theory of Cognitive Dissonance}

\subsection{Theory of Cognitive Dissonance and the Incentive of the New Generation}

The basic principle of theory of cognitive dissonance is that people have a tendency to a consistent or balanced [15]. When this pressure exceeds the affordability of the individual, the individual have the willingness to take measures to coordinate. In addition, there are three factors affecting the individual's motivation: degree of importance of disorders, degree of self-control, degree of rewards [9]. In the structure of grade, the employees of the new generation take measures based on their perception of relationships and power distance measures. [14]. To comfort of their own minds, they will seek cognitive coordination. According to theory of cognitive dissonance, encounter this uncoordinated, the employees of the new generation will take measures to reduce inconsistencies. In this case, they change their perception or change their behavior. For the target, managers can shape their behavior.

\subsection{Incentives under Theory of Cognitive Dissonance and the Structure of Grade}

In order to achieve the target incentive, managers lead their cognitive and behavioral (See Figure 4). Based on the function $\mathrm{M}=\mathrm{F}(\mathrm{R}, \mathrm{D}, \mathrm{T}=1)$ :

1) $M>0$

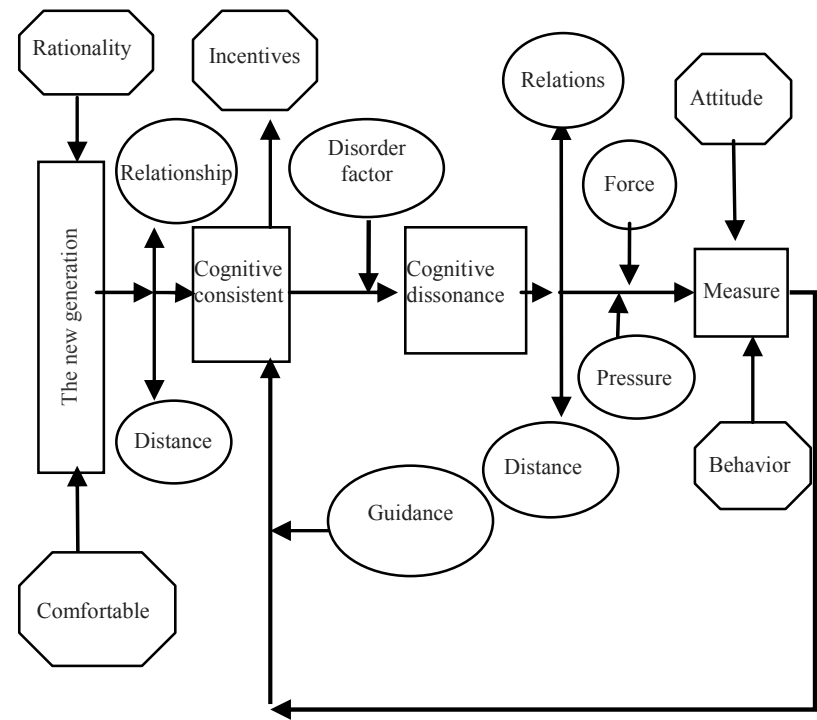

Figure 4. Incentives under theory of cognitive dissonance. 
At this point, managers do not need to motivate the new generation. Because they do not have cognitive dissonance or they can withstand the pressure.

2) $\mathrm{M}<0$ or $\mathrm{M}=0$

First, managers should make employees perceive that "we" are intimate. Second, leaders should let them believe that "you" are my skeleton staff. Finally, managers should make Employees feel that they are respectable in allocation of resources. In addition, scenario is complicated. In a complex scenario, managers need contingency management.

\section{Conclusions}

The incentive of the new generation employees is the world problem in dire need of solving in the labor market. Western society is a "group structure." Organization is a group, which is composed by a number of persons. In the same group, members of the group are equal and free. They do not pay attention to relations and power. For their own goals, they just need to improve their capabilities. However, our traditional society is the structure of grade and it is a country with horizontal and vertical structure [4]. Horizontal "layer" refers to the relationship, and vertical "sequence" refers to a power distance. In such a structure, they pay attention to relations and power. They ignored to improve their skills. So, we should have a broad vision to study it.

Western classical management theory is based on the special social, political, economic and technological environment. These theories are very important for us. However, we also build our own theoretical system. Therefore, this paper indicates the incentive problems of the new generation mainly from the perspective of the China's social structure (the structure of grade) and theory of cognitive dissonance.

\section{Acknowledgements}

This study is supported by the National Natural Science Foundation of China (11101265, 41171101, 61075115), National Social Science Fund (12BGL088), Shanghai Education Research and Innovation Key Project (14ZZ157).

\section{REFERENCES}

[1] A. J. Yang and Y. Q. Bai, "Motivation Theory Related Research Progress," Management \& Technology (HEAD),
No. 11, 2009, pp. 69-70.

[2] J. L. Xu, "An Interactive 'IAR' Incentive Model," Shanghai Jiaotong University (Social Science Edition), No. 1, 2000, pp. 46-53.

[3] M. C. Su and X. Q. Zhang, "Development and Trend Analysis on Incentive Theory," Science and Technology Management Research, No. 5, 2009, pp. 343-345, 339.

[4] Y. X. Yan, "Differential Pattern with Chinese Culture Class Concept," Sociological Research, No. 4, 2006, pp. 201-213, 245-246.

[5] J. D. Luo, "Relations and Circles-Chinese People Working in the Field of the Circle Phenomenon," Journal of Management, No. 2, 2012, pp. 165-171, 178.

[6] L. F. Jin and Y. H. Li, "On the Right after 90 Staff Management," Market Forum, No. 9, 2012, pp. 56-57.

[7] J. You and Y. C. Sun, "Chinese New Generation of Employees and Their Management," Wuxi Vocational and Technical College, No. 3, 2012, pp. 81-84, 90.

[8] X. Q. Hu, "Emotionally Moving: The New Generation of Workforce Management," New Capital, No. 3, 2010, pp. 16-20, 6.

[9] S. P. Robbins, ““'Principles of Management," China Renmin University Press, Beijing, 2004.

[10] H. J. Huang, L. Deng, N. Chen and Y. Lu, "On the '80' Research Literature Review," China Youth Research, No. 7, 2009, pp. 5-13.

[11] C. J. Yang, R. Liu and T. R. Li, "Multinational Why Expatriates Back after Leaving Office Frequently? WorkBased Embedding Theory Interpretation," Northeastern University (Social Science Edition), No. 1, 2013, pp. 44 49.

[12] X. Y. Zheng, "Employee Behavior after 90 Characteristics," Managers, No. 23, 2010, pp. 272, 251.

[13] H. J. Wang, "On a New Generation of Employee Incentive Ideas Change," Inner Mongolia Science Technology and Economy, No. 6, 2011, pp. 32-33.

[14] J. Ma, J. Wang and C. Yang, "Differential Pattern of Fairness and Performance Evaluation under the Employee Performance Relationship," Management Science, No. 4, 2012, pp. 56-68.

[15] G. Q. Xiang, "The Theory of Cognitive Dissonance Reflections,"Xuehai, No. 6, 2010, pp. 52-55. 